\title{
Asterina burtoni (Asteroidea; Echinodermata) in the Mediterranean and the Red Sea: Does asexual reproduction facilitate colonization?
}

\author{
S. Karako, Y. Achituv*, R. Perl-Treves, D. Katcoff \\ Faculty of Life Sciences, Bar Ilan University, Ramat Gan 52900, Israel
}

\begin{abstract}
The starfish Asterina burtoni is a Lessepsian colonizer which penetrated the Mediterranean Sea from the Red Sea. Populations of $A$. burtoni are found under rocks and stones in shallow waters along the northern Israeli and southern Lebanese Mediterranean coasts. In the Red Sea, $A$. burtoni is found in 2 forms, a pentamerous form with 5 equal arms that reproduces sexually, and a pluriradiate form with 3 to 8 arms of unequal length that reproduces both sexually and by fission. In the Mediterranean Sea only the pluriradiate fissiparous form is found. Only male gonads were observed in Mediterranean populations, suggesting reproduction by fission only. It is possible that the successful colonization of the Mediterranean by A. burtoni was mainly due to rapid proliferation by fissiparity. In the present study we used the random amplified polymorphic DNA (RAPD) method to address this question. Genetic diversity was determined within and between different pluriradiate populations from the Mediterranean and the Red Sea, and between the pentaradiate and the pluriradiate populations of the Red Sea. Our RAPD analysis revealed very low genetic diversity both within and between the localities in the Mediterranean, indicating clonal structure of these populations. These populations are similar to a fissiparous population from the south of the Gulf of Elat (Gulf of Aqaba), indicating that the probable origin of the Mediterranean populations is a fissiparous population from the Red Sea. On the other hand, there is high genetic diversity between the pentaradiate and the pluriradiate populations from Elat, at the north end of the Gulf of Elat. Phylogenetic trees based on these results distinguished between the populations from Elat and those of the Mediterranean, but did not show a clear separation between the 2 populations from Elat. This supported our assumption that the Israeli Mediterranean populations of this starfish are exclusively fissiparous, while in Elat the fissiparous population of $A$. burtoni also reproduces sexually.
\end{abstract}

KEY WORDS: Asterina $\cdot$ RAPD $\cdot$ Lessepsian migration

Resale or republication not permitted without written consent of the publisher

\section{INTRODUCTION}

The opening of the Suez Canal in 1869 created a connection between 2 different fauna, that of the Red Sea and that of the Mediterranean Sea. It also led to the colonization of the Mediterranean Sea by species from the Red Sea, which migrated via the Suez Canal. The term 'Lessepsian Migration' was coined by Por (1971) to describe the migration of biota through the Suez canal.

${ }^{*}$ Corresponding author. E-mail: achity@mail.biu.ac.il
Over 200 species, representing most phyla, were listed as Lessepsian migrants (Por 1978), and new species have been added to the list over the years (Galil 2000).

The starfish Asterina burtoni is one of the Lessepsian migrants that received scientific attention. Tortonese (1966) recorded the presence of this Indo-Pacific starfish in the Mediterranean, where it has been found along the coasts of Lebanon and Israel. In the Red Sea, 2 forms of $A$. burtoni are known (Clark 1952, Tortonese 1960): a pentaradiate form with 5 equal arms, and a pluriradiate form with 3 to 8 arms of different length. Another difference between these forms is the number 
of madreporites. Whereas the pentaradiate specimens have only 1 madreporite, the pluriradiate specimens have a variable number of madreporites. Their number is sometimes, but not always, equal to that of the arms (Clark 1967). Clark (1952) and Tortonese (1960) suggested that the 2 morphological forms of the starfish A. burtoni belong to the same species, and that the pluriradiate form represents young specimens that reproduce by fission. While growing, the starfish change into the pentradiate form that reproduces sexually. In 1952 Clark stated that there is no evidence to affirm the existence of a transitory stage form. Achituv (1969) suggested that the differences between the 2 forms justify specific separation; however, Clark \& Rowe (1971) did not accept this suggestion. Emson \& Wilkie (1980) claimed that in individuals of large body size, the collagen connection between the skeleton plates is particularly strong, and fissiparity becomes difficult or impossible.

Colonization and the establishment of new populations depend on the reproductive success of the founding population. Achituv \& Sher (1991) suggested that fissiparity provides a mechanism for rapid colonization of new environments through the production of multiple copies of genotypes that are adapted to local conditions. Using electrophoretic analysis of polymorphic enzymes, Johnson \& Threlfall (1987) showed that local populations of the starfish Coscinasterias calamaria from western Australia exhibit low genotypic diversity. Their results confirm the clonal structure of the local population. This highly clonal structure indicates that asexual proliferation predominates over larval recruitment.

Molecular markers can be used to reveal polymorphisms at the DNA level between and within populations of different taxa (Richardson et al. 1995). Changes in nucleotide sequences are used in molecular evolutionary studies both for estimating the rate of evolution and for reconstructing the evolutionary history of organisms ( $\mathrm{Li} \&$ Graur 1991). Some of these techniques can be applied for comparisons between populations and between individuals in the same populations. The random amplified polymorphic DNA (RAPD) technique (Williams et al. 1990) has been recognized as a useful tool for population studies (Caetano-Anollés 1993). RAPD requires only minute quantities of genomic DNA, and short synthetic oligonucleotides of random sequence (Williams et al. 1993). RAPD has been used in taxonomic, evolutionary and ecological studies, e.g. to separate sympatric populations of sibling species of the periwinkles Littorina (Crossland et al. 1993), parthenogenetic populations of the cladocerans (Hellsten \& Sundberg 2000), parthenogenetic and sexually reproducing populations of aphids (Martinez-Torres et al. 1997) and aphid clones (Fuller et al. 1999, Simon et al. 1999).
In the present study we applied RAPD analysis to several populations of Asterina burtoni from both the Mediterranean and the Red Sea and used the genetic distance data to gain new insight into the evolution and migration of this species. We addressed 2 specific questions: (1) Does the Mediterranean population of the starfish $A$. burtoni consist of 1 or several clones, which reproduce only by fissiparity? (2) Should we consider the 2 forms of $A$. burtoni from the Red Sea as 2 different species?

\section{MATERIALS AND METHODS}

Starfish. Samples of Asterina burtoni for RAPD analysis were collected in shallow water under stones in the Red Sea and the Mediterranean coast of Israel (Fig. 1). Pluriradiate fissiparous individuals were collected from Elat at the northern tip of the Gulf of Elat ( $n=16)$, and from El Fauz at the southern part of the gulf $(\mathrm{n}=11)$. Pentaradiate individuals were collected

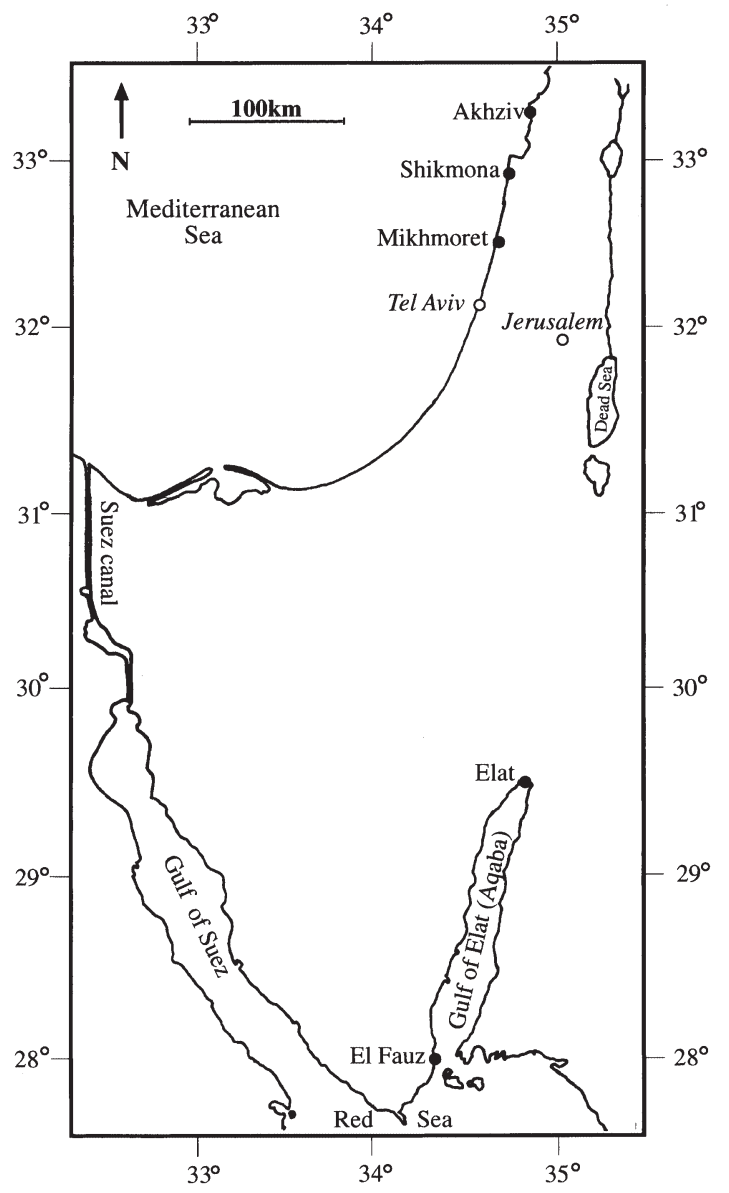

Fig. 1. Locations along the Mediterranean coast and the Red Sea (Gulf of Elat) where Asterina burtoni was collected. The location of Tel Aviv and Jerusalem are given for orientation 
from Elat $(\mathrm{n}=16)$. In the Mediterranean Sea, samples were collected in shallow waters near Akhziv $(n=16)$, Shikmona ( $\mathrm{n}=16)$ and Mikhmoret $(\mathrm{n}=15)$. The starfish were transferred to the laboratory, where they were kept in aerated seawater. They were numbered and for identification of locality, a prefix was added to the number: 'A' for Akhziv, 'S' for Shikmona, 'M' for Mikhmoret, ' $E$ ' for the pentamerous starfishes from Elat, 'EF' for fissiparous starfish from Elat, and 'EL' for El Fauz.

DNA extraction and polymerase chain reaction (PCR). The soft tissue, stomach and pyloric caecae, of each starfish was removed and separated from the skeleton. The DNA was extracted using a High Pure PCR Template Preparation Kit (Roche). For RAPD amplification (Williams et al. 1993), approximately $30 \mathrm{ng}$ of genomic DNA were amplified in a $25 \mu$ reaction mixture containing $2.5 \mathrm{mM} \mathrm{\mu l}^{-1} \mathrm{dNTPs}, 0.5 \mathrm{U}$ Taq DNA Polymerase (Appligene), $10 \mathrm{mM}$ Tris $\mathrm{HCl}(\mathrm{PH}=7.5)$, $50 \mathrm{mM} \mathrm{KCl}, 1.5 \mathrm{mM} \mathrm{MgCl}_{2}, 0.1 \%$ Triton $\times 100$ and $0.2 \mathrm{mg} \mathrm{ml}^{-1} \mathrm{BSA}$, and $5.2 \mathrm{pmol}$ primer. The samples were subjected to 1 cycle of denaturation at $94^{\circ} \mathrm{C}$ for $3 \mathrm{~min}$, followed by 40 cycles at $36^{\circ} \mathrm{C}$ for $1.5 \mathrm{~min}$ (annealing step), $72^{\circ} \mathrm{C}$ for 2 min (extension step), and $94^{\circ} \mathrm{C}$ for $1 \mathrm{~min}$ (denaturation step). The program was completed by $1 \mathrm{~min}$ at $36^{\circ} \mathrm{C}$ and $3 \mathrm{~min}$ at $72^{\circ} \mathrm{C}$. Reaction products were separated by electrophoresis in $2 \%$ agarose gels in TBE and visualized by ethidium bromide staining.

In order to find primers that are suitable for the analysis of the starfish Asterina burtoni, we screened 200 random decamer primers (University of British Columbia Biotechnology Laboratories, Vancouver). The following 7 primers were selected and used for the the analysis of the populations of Akhziv, Shikmona, Mikhmoret, and the pentamerous and the fissiparous starfishfrom Elat: Primer $104-{ }^{5}$ GGG CAA TGA T ${ }^{3^{\prime}}$; Primer 116 - ${ }^{5}$ TAC GAT GAC G ${ }^{3^{\prime}}$; Primer 132 ${ }^{5}$ AGGGATCTCC $^{3}$; Primer 148 - ${ }^{5^{\prime}} \mathrm{TGTCCACCAG}^{3^{\prime}}$; Primer $159-{ }^{5^{\prime}} \mathrm{GAGCCCGTAG}^{3^{\prime}}$; Primer $160-{ }^{5^{\prime} \mathrm{CGAT}-}$ TAAGAG ${ }^{3}$; Primer $363-{ }^{5^{\prime}}$ ATGACGTTGA ${ }^{3}$. For the El Fauz population we used only Primers 104, 116 and 363. Control reactions without template DNA were run alongside the experimental samples.

Data analysis. RAPD analysis was first performed on 79 specimens collected from 3 localities in the Mediterranean Sea and the 2 populations from Elat. These were screened using all 7 primers. Bands were scored, by eye, as present (1) or absent (0). An additional 11 specimens from El Fauz were compared to the 47 starfish from the Mediterranean using 3 of the primers. The resulting data matrix was used as input for parsimony analysis. The 2 character states (present, absent) were taken as unordered. Trees were constructed as unrooted. Equal weight was assigned to each charac- ter (band). Computation of genetic distances between taxa and parsimony analysis were performed using the PAUP program (Swofford 1993).

\section{RESULTS}

From the different populations, 79 starfish were collected from locations in the Red Sea and the Mediterranean Sea (Fig. 1). Their DNA was isolated and used for RAPD analysis. The average number of bands identified per primer was 8.5. A total of 185 bands between 100 and 1400 nucleotide pairs long were scored. All the primers yielded the same band patterns in all the specimens from the Mediterranean Sea, while different patterns were displayed in the populations from the Red Sea. All of the 185 bands scored (100\%) were polymorphic among the 32 specimens from Elat, while only $4.6 \%$ appeared to be polymorphic among the 47 specimens taken from the Mediterranean Sea. Fig. 2 shows a typical RAPD banding pattern for 1 primer in samples taken from 15 pentamerous starfish from Elat and 2 fissiparous from Shikmona. The pattern variation between individuals is evident. Fig. 3 compares RAPD patterns obtained from the fissiparous starfish from the Mediterranean (Fig. 3A) and Elat (Fig. 3B) using another primer. While the banding pattern varies among samples collected in Elat, it is uniform among those from the Mediterranean. The relationship among the starfish was analyzed using parsimony analysis (PAUP program), in which only phylogenetically informative characters are used to construct the shortest tree, by stepwise addition of taxa and characters. The polymorphic 185 bands were used, and the data yielded 13 shortest trees of 815 steps long. Fig. 4A shows 1 of these trees. The majority-rule consensus tree in Fig. 4B shows that the 13 shortest trees that we obtained from our data are nearly identical. In all the

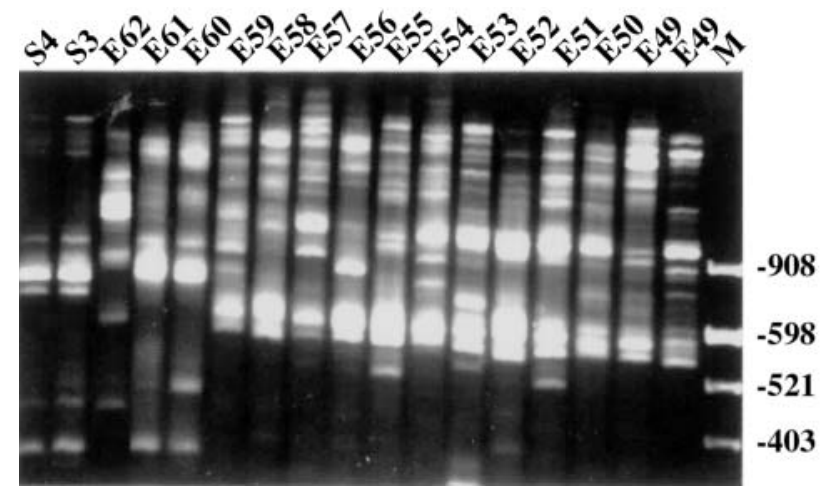

Fig. 2. Asterina burtoni. Example of RAPD profiles obtained with Primer 116 using DNA from non-fissiparous (pentamerous) specimens from Elat, Red Sea (E) and 2 specimens from Shikmona (S). M: molecular weight standards 
A

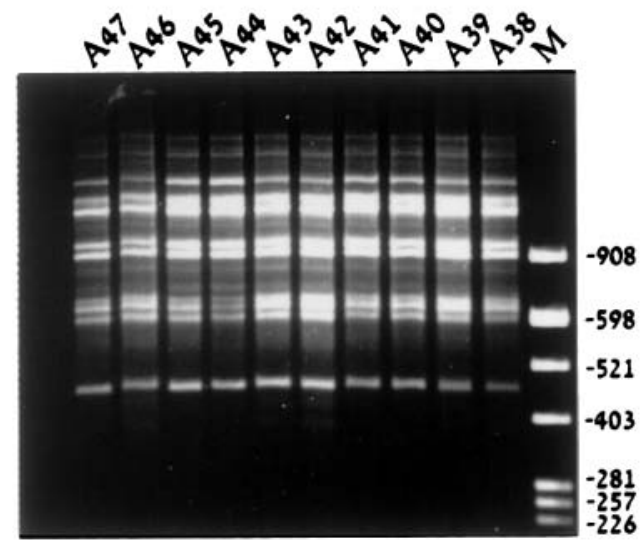

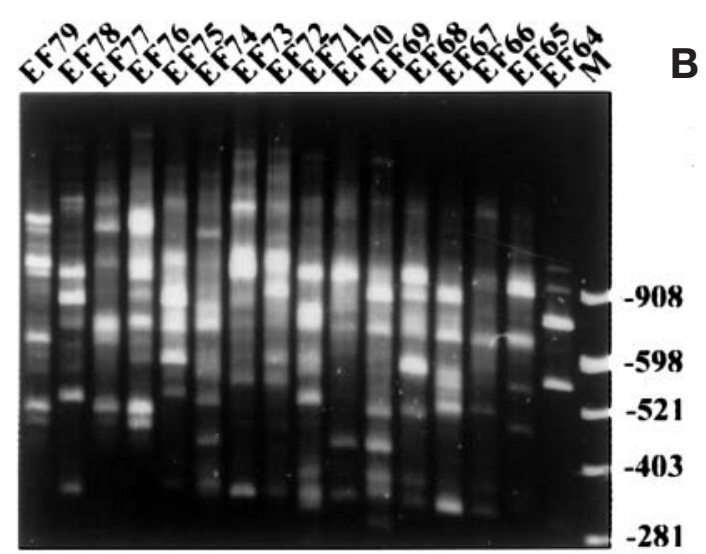

Fig. 3. Asterina burtoni. Example of RAPD profiles obtained with Primer 104 using DNA from fissiparous specimens as template. (A) from Akhziv; (B) from Elat, Red Sea. M: molecular weight standards

shortest trees, the starfish from the Mediterranean Sea are separated from those of the Red Sea by a node of 34 steps.

The above results, showing identical banding patterns in all the specimens collected along the Mediterranean coast of Israel, led to the analysis of a fissiparous population of Asterina burtoni found at El Fauz, on the Sinai coast, in the south of the Gulf of Elat. Due to the limited amount of material from El Fauz and to technical difficulties, we were able to use only 3 primers for this comparison. The average number of bands identified per primer was 8 . A total of 24 bands were scored and only 2 of them $(8.3 \%)$ were polymorphic. This low level of polymorphism suggested a clonal structure of the El Fauz population. Moreover, the patterns of bands were identical between the specimens from El Fauz and those of the Mediterranean specimens from Shikmona, Akhziv and Mikhmoret. Fig. 5 provides an example of RAPD patterns obtained for these samples.

\section{DISCUSSION}

In the present study, the genetic diversity of 3 Mediterranean and 2 Red Sea populations of Asterina burtoni were compared. The first objective was to use molecular markers to evaluate the penetration and the successful colonization of the Mediterranean by this starfish. This colonization depended on its ability to reproduce asexually, characterized by low genetic diversity. The second objective was to elucidate the taxonomic relationship of the 2 morphs of A. burtoni.

Analysis of the band patterns, and parsimony analysis by the PAUP program revealed strong similarity between the 3 populations collected in the northern part of the Mediterranean coast of Israel. Moreover, comparison of the population of El Fauz, near the southern end of the Gulf of Elat, with those of the Mediterranean indicates that it is likely that there is a relationship between these populations. Both genetically and geographically distinct from the 2 populations collected from Elat, at the northern end of the Red Sea. The polymorphism of the populations from Akhziv, Shikmona and Mikhmoret is very low, $4.6 \%$, compared to $100 \%$ in the Elat populations. This low level of polymorphism may in fact indicate genetic identity and a common source of all the individuals collected from the Mediterranean. These results support the assumption that the Mediterranean population of Asterina burtoni from the Israeli coast reproduce merely by fission and not by sexual reproduction. Achituv \& Sher (1991) found only male specimens in Shikmona and concluded that the population of Shikmona reproduces only by fissiparity. A highly skewed sex ratio reflects clonal structure of a population (Johnson \& Threlfall 1987).

The polymorphism found in the populations from Eilat, both among the fissiparous and the non-fissiparous forms, was very high with all the primers tested. Two nodes of 13 and 10 steps, respectively, separate most of the fissiparous individuals from the pentamerous ones, but the separation is not complete, and the 2 forms are present in both branches (Fig. 4). The high diversity of banding patterns of the fissiparous form from Elat probably indicates that this form reproduces both sexually and asexually. Achituv (1973a,b) reported the presence of male and female mature gonads among the fissiparous starfishes from Elat, supporting a sexual mode of reproduction.

The population from El Fauz, at the southern end of the Gulf of Elat, was very uniform, suggesting clonal structure and indicating the possibile presence of asexual populations in the Red Sea. The polymorphism (based on 3 primers) of the population from El Fauz was very low (8.3\%). Achituv \& Sher (1991) suggested that the absence of females in the Mediterranean pop- 


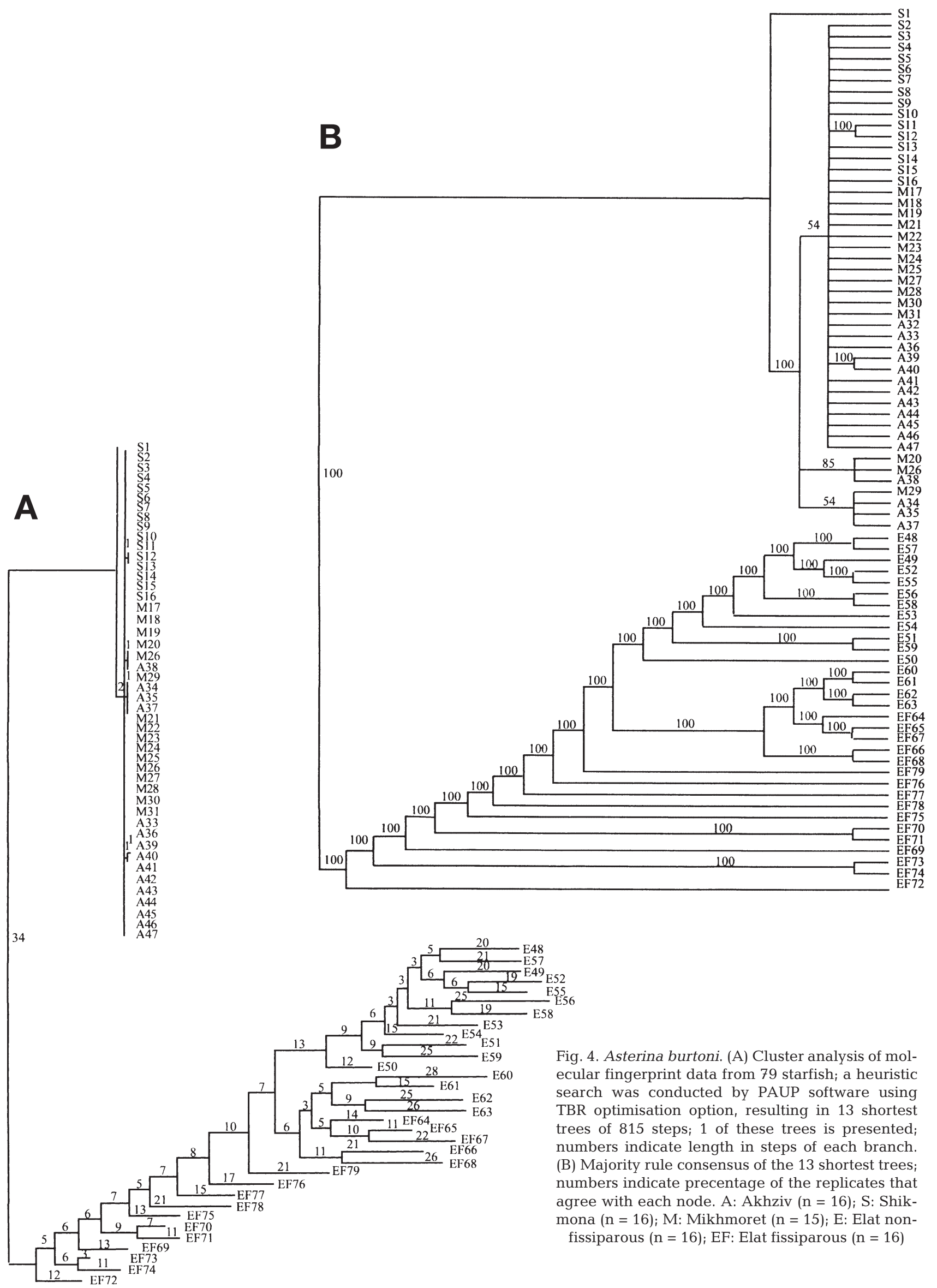




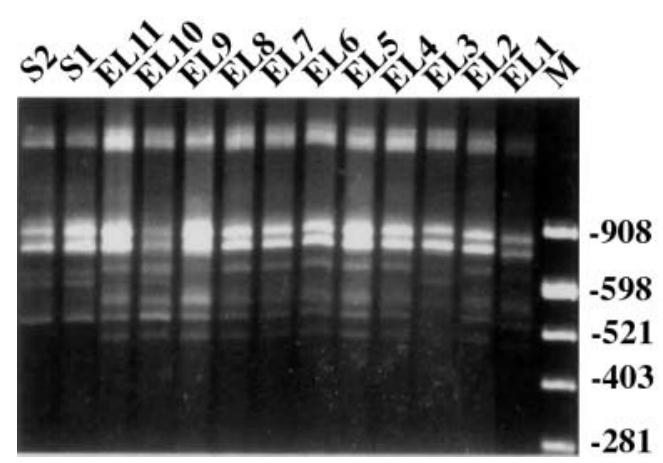

Fig. 5. Asterina burtoni. Example of RAPD profiles obtained with Primer 116 from 11 fissiparous specimens from El Fauz (EL) and 2 specimens from Shikmona (S). M: molecular weight standards

ulations might indicate that these originated from a single propagule, which established those populations. The finding of a fissiparous asexual population of Asterina burtoni in the Red Sea and its genetic similarity to the Mediterranean populations may suggest, on the other hand, that the Mediterranean populations originated from a fissiparous population that already existed in the Red Sea. The fissiparous starfish Coscinasterias calamaria presents a different pattern of population structure. In this species, Johnson \& Threlfall (1987) showed large differences in clonal composition among populations found $50 \mathrm{~m}$ apart, indicating that clones of individuals of asexual origin do not mix over large distances. Their results also suggest that the clonal diversity resulted from sexual reproduction. Our study, showing low genetic diversity over a wide geographic range, differs from the finding of Johnson \& Threlfall, indicating that fission played an important role in the establishment of the Mediterranean populations of A. burtoni.

Fissiparity, which produces highly viable propagules, may have been at the basis of the successful colonization of the Mediterranean by Asterina burtoni. This is in contrast to the findings of Safriel \& Ritte (1983), who suggested that success in colonization depends on the ' $r$ ' strategy, which implies a large number of small propagules. For a Lessepsian migrant the establishment of Mediterranean populations depended on the ability of propagules to cross the obstacle presented by the Suez Canal, find a niche in the new ecosystem and occupy it by successful reproduction (Por 1978). In the case of $A$. burtoni, this was achieved most probably by a small asexually reproducing founding population of genetically identical individuals. The source of the founding population was probably a Red Sea fissiparous population like that of El Fauz that may have become established also along the Gulf of Suez. Future exploration along the Gulf of
Suez and the Suez Canal may result in the tracing of such a population and its route of migration.

Our results did not show a clear genetic separation between the 2 forms in the Red Sea and thus do not support Achituv's (1969) suggestion of specific separation of the 2 morphs. The high degree of polymorphism found within the 2 populations from Elat is rather unusual in intra-specific situations, and apparently an accurate measurement of the distance between them was not achieved by RAPD: a less variable technique such as restriction fragment length polymorphism RFLP, or the comparison of a specific DNA sequence, would be more suitable for this purpose.

Acknowledgements. We thank Dr. Irina Kovalsky and Dr. Gitit Hershkovitz for their assistance. Mr. Oren Levy and Ms. Noa Blecher-Simon helped us in the collection of the starfish. This study was supported by the committee for the advancement of research, Bar Ilan University.

\section{LITERATURE CITED}

Achituv Y (1969) Studies on the reproduction and distribution of Asterina burtoni Gray and A. wega Perrier (Asteroidea) in the Red Sea and the eastern Mediterranean. Isr J Zool 18:329-342

Achituv Y (1973a) On the distribution and variability of the Indo-Pacific sea star Asterina wega (Echinodermata, Asteroidae) in the Mediterranean Sea. Mar Biol 18: 333-336

Achituv Y (1973b) The genital cycle of Asterina burtoni Gray (Asteroidea) from the Gulf of Elat, Red Sea. Cah Biol Mar 14:547-553

Achituv Y, Sher E (1991) Sexual reproduction and fission in the sea star Asterina burtoni from the Mediterranean coast of Israel. Bull Mar Sci 48:670-678

Caetano-Anollés G (1993) Amplifying DNA with arbitrary oligonucleotide primers. PCR Meth Appl. 3:85-94

Clark AM (1952) The 'Manihine' expedition to the Gulf of Aqaba. VII. Echinodermata. Bull Br Mus (Nat Hist) Zool 1: $203-214$

Clark AM (1967) Variable symetry in fissiparous Asterozoa. Proc Symp Zool Soc Lond 20:143-157

Clark AM, Rowe FWE (1971) Monograph of shallow water Indo-West Pacific echinoderms. Trustees of the British Museum (Natural History), London

Crossland S, Coates D, Grahame J, Mill PJ (1993) Use of random amplified polymorphic DNAs (RAPDs) in separating two sibling species of Littorina. Mar Ecol Prog Ser 96: 301-305

Emson RH, Wilkie IC (1980) Fission and autotomy in echinoderms. Oceanogr Mar Biol Annu Rev 18:155-250

Fuller SJ, Chavigny P, Lapchin LL, Vanlerberghe-Masutti F (1999) Variation in clonal diversity in glasshouse infestations of the aphid, Aphis gossypii Glover in southern France. Mol Ecol 8:1867-1877

Galil BS (2000) Lessepsian immigration: human impact on Levantine biogeography. In: von Vaupel Klein JC, Schram FR (eds) The biodiversity crisis and Crustacea. AA Balkema, Rotterdam, p 47-54

Hellsten ME, Sundberg P (2000) Genetic variation in two sympatric European populations of Bosmina spp. (Clado- 
cera) tested with RAPD markers. Hydrobiologia 421: $157-164$

Johnson MS, Threlfall TJ (1987) Fissiparity and population genetics of Coscinasterias calamaria. Mar Biol 93:517-525

Li WH, Graur D (1991) Fundamentals of molecular evolution. Sinauer, Sunderland, MA

Martinez-Torres D, Carrio R, Latorre A, Simon JC, Hermoso A, Moya A (1997) Assessing the nucleotide diversity of three aphid species by RAPD. J Evol Biol 10:459-477

Por FD (1971) One hundred years of Suez Canal - a century of Lessepsian migration: retrospect and viewpoints. Syst Zool 20:138-159

Por FD (1978) Lessepsian migration - the influx of Red Sea biota into the Mediterranean by the way of the Suez Canal. Springer-Verlag, Berlin

Richardson T, Cato S, Ramser J, Kahl G, Weising K (1995) Hybridization of microsatellites to RAPD: a new source of polymorphic markers. Nucleic Acids Res 23:3798-3799

Safriel UN, Ritte U (1983) Universal correlates of colonizing ability. In: Swingland IR, Greenwood PJ (eds) The

Editorial responsibility: Simon Archer (Contributing Editor), Guildford, United Kingdom ecology of animal movement. Clarendon Press, Oxford, p 215-239

Simon JC, Leterme N, Latorre A (1999) Molecular markers linked to breeding system differences in segregating and natural populations of the ceral aphid Rhopalosiphum padi L. Mol Ecol 8:965-973

Swofford DL (1993) PAUP: phylogenetic analysis using parsimony, Version 3.11. Illinois Natural History Museum, Champaign, IL

Tortonese E (1960) Echinoderms from the Red Sea. I. Asteroidea. Bull Sea Fish Res Stn Israel 29:17-23

Tortonese E (1966) Echinoderms from the coast of Lebanon. Misc Pap Nat Sci Am Univ Beirut 5:2-5

Williams JGK, Kubelik AR, Livak KJ, Rafalski JA, Tingey SV (1990) DNA polymorphism amplified by arbitrary primers are useful as genetic markers. Nucleic Acids Res 18: 6531-6535

Williams JGK, Hanafey KM, Rafalski JA, Tingey SV (1993) Genetic analysis using random amplified polymorphic DNA markers. Methods Enzymol 218:705-741

Submitted: May 9, 2001; Accepted: January 17, 2002

Proofs received from author(s): May 3, 2002 